\title{
The Riches in various data banks on poverty: a comparative study on the assessment of poverty measurements around the globe
}

\author{
drs. J.C.M. de Bekker, Medical Anthropologist ${ }^{1, *}$ \\ ${ }^{1}$ Leiden Ethnosystems And Development Programme, Faculty of Science, Leiden University \\ *Corresponding author: hansdebekker@hotmail.com
}

\section{ABSTRACT}

In the context of Integrated Microfinance Management and Sustainable Development, establishing the impact of such interventions is a challenging endeavour. Such an approach is substantiated by the degree to which the poverty-related phenomena are measurable, or whether they can be measured at all. In contribution to the implementation of the IMM concept, the objective is to elaborate on the way in which development is currently expressed, and in particular the way in which poverty is being defined and measured up until today. In order to make this topic tangible, the recent changes and evolution of the parameters which are underlying this definition are referred to e.g. the Human Development Index (HDI), the International Poverty Line (IPL), the Purchasing Power Parity Exchange Rate (PPP), or the Multidimensional Poverty Index (OPHI), among others. In addition, an analogy is presented to the anthropological characteristic of the LEAD approach, i.e. the LEAD School of Ethnoscience. Even though the mentioned parameters are widely used and standardised to a large extent, they are all indicator instruments which, even by their respective promoters, are considered to have their shortcomings. They need to be considered in relationship to the purpose they have of expressing the transition of one state of (well-)being to the next. Although most attention is usually paid to the limitations of their discriminating ability, the eligibility of a number of these parameters is consequently presented. The literature has ample descriptions of inventive proxy variables, workarounds and substitutes. There is, however, no specifically targeted criticism because of such approach. This paper seeks to contribute to the understanding and consensus on the applicability of some parameters, or their alternatives.
Keywords: integrated microfinance, sustainable development, impact measurement

\section{INTRODUCTION}

It is important to know the implications of expressing the living standard and well-being in terms of numerical values of consumption of food, shelter, physical household assets, as well as health status, education or life expectancy. Ultimately, whether the experience of poverty could be expressed in terms which are consistent with the perception of the people who suffer. In order to enable the discussion, certain examples of measurement are taken from recent publications such as of the World Bank's International Comparison Programme (2011), The World Economic Forum (2015), the Bretton Woods Project (2014), The Indian Express (2015), and UNDP's Human Development Report (2015). A comparison is made of the indicators which were used and the motivation of the authors concerned. There is attention for the methodological implications of international, regional, local rural and urban differences, as well as time / periodical aspects or subjective cultural influences. The paper seeks the feasibility of incorporating objective (material) indicators along with subjective indicators, and deliberates on the choice of indicators and their intrinsic and semantic value in the description of poverty. The recent lifting of the threshold of poverty from $\$ 1.25$ to $\$ 1.90$ a day (World Bank 2011) has sparked a range of reflections on the development and applicability of the indices used by several organisations to display the world's imbalance of living standards. The poor people distribution over continents is currently estimated as 
$551 \quad$ Million in Asia

436 Million in Africa

15 Million in South America

5.9 Million in North America

0.3 Million in Europe

50 Thousand in Oceania

(Table cf. Max Roser, OurWorldinData.org, 2016, Oxford $U K)$

\section{THE POVERTY PARADIGM SHIFT}

Over the years the discussion on how to measure poverty has seen a gradual shift from finding consensus on concrete figures such as income, consumption quota or material assets (translated whenever possible in monetary terms) into more complementary indices such as access to material and immaterial resources (e.g. education, health care, social networks) or the influence of environmental conditions. The initial reference was the poverty line, established through the calculated average of a number of poor countries by the World Development Report (1990). The tools focusing on monetary aspects like GDP, PPP, FGT (Foster Greer Thorbecke index), Gini-coefficient, among others are all macro-economic constructs which serve the purpose of making comparisons across economies and regions. The movement to extend this type of reference has led to discussions on the development of new sets of indicators which encompass more than income, food or combined indicators which enable a classification of a living standard, comprising subjective attributes such as (physical and mental-) well-being, life satisfaction, connectedness, safety, equal rights, among others. The second discussion has to do with the distinction between the level of measurement, such as community level, household level, or individual level (and recently: satellite imaging). The third discussion could be described as the time perspective; the influence of a state of poverty seems to have a larger impact as the conditions are experienced for a longer period of time (e.g. four consecutive years, Gesthuizen 2006, Di Tella et al 2007, Otten et al 2014), sometimes also related to the transitions that can be experienced in a certain (cultural) area in terms of climate or ecological changes, or deprivation through social conflict (e.g. South Sudan as of 2014). It also refers to the concept of a so called "shockproof" condition, meaning that the poverty is expressed in the degree to which a household can survive a temporary setback in means of living (usually caused by an external agent), and the time it takes to overcome that status (Ravallion 2015) without external input. It is also important to consider the semantic differences between 'poverty' and related terms such as social exclusion, marginalisation, well-being, life satisfaction, happiness or inequality, which may all be attributes of a condition of 'poverty' that are measured by the same parameters but cannot be used interchangeably. A number of these attributes have since the eighties been included in the set as a result of the search for non-monetary aspects.

The challenge which runs along in the background is not so much the development of measurement instruments which are valid as an individual gauging device, but whether they can be applicable on a global level. The idea is that even though poverty is experienced in a certain geographically defined area, the methodologically valid comparison with other geographical areas turns it into a universal and tangible phenomenon which could be addressed by a combined effort of political will and commitment. After all, the Yanomamö along the banks of the Orinoco were selfsustaining to a large extent without having any reference to comparable situations outside their area (Good 1997), and most of the Kurya people of Ikorongo always had food because they engage in hunting, herding, farming and poultry simultaneously, also when there was no money changing hands (Shetler1996), but neither group called itself "poor" because there was no reference to validate the term.

The need for global comparison however could theoretically be turned around 180 degrees by maintaining that the perception of the local people with regard to their living conditions as being 'positive' or 'negative', in view of their own long term survival, is an alternative acceptable gauging device. If that were the consensus, there would be no need to develop a comparable scale in absolute numbers, but we would could make do with an ordinal variable that read 'bad sufficient - good', and have it scored by our groups of respondents in order to establish their relative living standard. To exemplify this The Gallup Organisation organised something similar by a World Poll in 2006 whereby the respondents were asked to rate their satisfaction with their standard of living on an ordinal scale, and these were later compared with the income distribution in the same areas, a post hoc connection with a monetary measurement item. Though all authors concerned agree that there is a wider range of factors which determine this level of satisfaction, they could probably not be reduced to one single denominator (Deaton 2008, Roser 2016). In the light of that 
discussion the notion of "sequence" is introduced, i.e. once basic needs are filled in properly, the attention shifts to a different type of personal development, through better access to resources, and therewith the satisfaction increases (the underlying idea being that once absolute poverty has been subsided, additional income does not lead to more satisfaction (not: "happiness"), but social inclusion or vertical mobility might, Ed.).

If the correlation between a higher average income and higher living standard satisfaction is not obvious from research data, it is interesting whether the opposite could be maintained. Fact remains however that low income countries display less satisfaction than high income countries overall (Deaton 2008). Furthermore, Deaton shows in his paper that there is no cut off above which level there is no increase in satisfaction as national income goes up; contradicting the hypothesis on basic needs (the 'sequence'). Having established that however, he follows his interpretation stating that the highest gain in satisfaction levels is with low income countries as income increases. That would indicate that the biggest proportional advance is made inside the lower brackets of the poverty scale, while the correlation stays linear further up. Finally the most important conclusion would have to be that he finds there is no positive relationship between increase in life satisfaction and economic growth rates, although it should be stressed that in this example there is no focus on a rural low income country sample, but a global tendency.

\section{Table 1. Checklist for exploratory semi-structured interviews in Peru}

There have been more instances where scientist have tried to develop indices that were outside the monetary sphere, not necessarily to 'define' poverty as such, but to establish whether people experience their living conditions as acceptable or not via indirect assessments. Referring to the work of Copestake and Camfield (2009), there is a concept of 'well-being' through the use of 'a life goal satisfaction approach' which is worked out for several countries. In the process the respondents were asked open ended questions in a style analogous to the anthropological method of semantic differentiation scales, based on their perceptions of achievement, but without inherent classification. They then used the weighting of the scores per country of study in mutual comparison as a basis to compose an overall analysis, also taking into account the contextual feedback of the researchers on their fieldwork experience in the respective countries. The next significant example of incorporating non-economic-monetary indices is found in the Oxford Poverty \& Human Development Initiative (OPHI) (Alkire \& Foster 2010). The global MPI was developed by OPHI with the UN Development Programme (UNDP) to be used in the Human Development Report in 2010. In that model, indices like health, sanitation, education and living standard have been taken up in a list of ten variables. In their methodology the weighting (of which the mathematical rationale is not explained here Ed.) is done on a number of the complementary parameters whereby the lack of access ('deprivation') has to be one third of the total scaling in order to be assessed as poor, whereby the measurement is done on an individual level, while there is also an indication of intensity, expressed through the number of deprivations. This specific set of indicators has apparently seen constant evolution as the current set is described as the fourth generation. This approach is in the direction of contextual and environmental parameters but does not show an integration of subjective measurement.

\section{Table 2. The deprivation threshold of those who are both MPI poor and destitute}

As the conventional type of data are commonly used in ethnographic fieldwork, it was interesting to note that during fieldwork in Tanzania (Mara 2015) the designation of the local research assistants of the households they interviewed, often deviated from the other variables which were used as SES indicators, i.c. regular income, additional income (from side activities), and self-assessed status (poor-average-rich) as they were answered by the household heads themselves. In a number of cases the research assistants had classified these as 'poor' where the household had used 'very poor' and also 'average' where the household had used 'poor'. These designations were again sometimes inconsistent from the income intervals whereby the 50.000 shilling scaled slots (very poor-poor-averagerich-very rich) were designated by the local council's education inspectors on the basis of their community experience. And here too, households were often not in the income category where they were expected to be on the basis of their self-assessment, or the assistants' designation. That provided insight into the subjectivity of the categorisation (Data: Serengeti Fieldwork, 2015, Ed.)

\section{Table 3. SES Categorization}


When extended to other assets such as land and cattle however the picture becomes more consistent with the data. To illustrate the case there were households consisting of elderly people supervising grandchildren that did not have any registered income or assets, but stated they had complete satisfaction because there were ample (family-related) resources in land and livestock, and "there was food on the table very day". It is the type of example that underlies the discussion on mixing income and consumption in the World Bank's Povcal.Net database, and as Roser (2016) comments, it shows that the difference in the consumption comparison is smaller than the one on income.

Another factor that has to be taken into account is where individual household members may have a different status from a household's overall assessment. It would methodologically be sound to interview individuals and have their individual response as the outcome by which the categorisation is to take place. It would also emphasise the usefulness (in applicability) of subjective indicators of poverty, like accessibility of provisions, state of health, education level, the experience of social exclusion, or the degree of satisfaction with a certain lifestyle, since they would ideally be measured on a personal level to begin with.

As an illustration of the direct opposite, more recently, scientists of Stanford University (Burke et al, Science Magazine, August 2016) analysed satellite imaging data, and found that the combination of infrastructural quality, taken as road accessibility, road surface quality (paved, unpaved, potholes) and housing rooftop material (thatch, sheets, tiles), proved to be reliable indicators of poverty. Again though, they were validated post hoc in the context of traditional economic numerical standards, by comparing them to the available data from household surveys in the same area. The motivation of considering these type of indicators has an additional logistical dimension, namely that such kind of aerial monitoring could be done very swiftly, and truly globally, without having to undertake labour intensive household surveys. That means that the absence of data could be compensated provided that the said parameters are proven to be globally applicable.

\section{DISCUSSION}

To present an overview of the main indicators currently used the following matrix shows the type and the categorisation as they were extended with new owns over time. The purpose of finding measurements which can discriminate between standards of living and have a global applicability is for the sake of comparison and reaching consensus (cf. 'Absolute poverty'), or, ultimately to devise policies that lead to a more equal distribution of the world's resources. If there is no mechanism to achieve this, then there should be a way of making a local phenomenon transferrable in terms of intrinsic value, analogue to what the PPP Exchange Rate concept tries to do. The suggestion here is making a projection whereby the perception of a certain population is the vantage point but is yet comparable to the perception of another population in another area (cf. 'Relative Poverty').

Another mechanism to achieve "model reduction" is to focus only on the 'poorest of the poor' (Robinson 2002), as is instrumental in the context of implementing integrated microfinance. That would theoretically eliminate the necessity to have a comparison across borders, expressed in numerical values, as the distance to the local peer group, i.e. those that are doing moderately well or above, becomes the criterion. It also eliminates certain methodological problems such as unrepresentative sampling. If a bias is created on national level data by lack of response in specific layers of society, the focus on smaller units on community level could maintain its validity. It would simultaneously take away the intraregional bias between urban and rural, because the evaluation would be made as it would be in a case study. In this case it is well to remember that urban poor are often worse off than rural poor, because of the often 'invisible' resources for survival such as land, livestock and extended family members which are probably absent in an urban environment. This distinction carries the intricacy of being linked to another parameter in demographic data, i.e. the influence of urbanisation in otherwise predominantly rural settings (infrastructural parameters become very interesting in that situation as the physical distance to facilities would be limited yet there could be no access to possible benefits, e.g. the favelas in Sao Paulo, or similar conditions in a metropolis like Lagos or Manilla).

\section{Table 4. Variable measurements}

\section{CONCLUDING REMARKS}

Finally, to make the connection with the school of Ethnoscience as advocated by the LEAD programme Leiden University, it is the perception of their condition by the people themselves that becomes the targeted approach. It has been established that there is a 
correlation between self-assessment of living conditions and income levels (Ravallion 2016) that is consistent over boundaries, and that participation of the respondents in their assessment as a method is complex but sustainable ('Participatory Rapid Appraisal' - PRA, cf. White and Pettit 2004). The challenge then may be shifted to another sphere, namely that the correlation (Copestake et al. 2007) between subjective measurements based on individual experience and economic numerical ones can be established to the extent that both can be used simultaneously and complementary. What we have seen in this overview is that on several occasions investigators have attempted to add Ethnoscience based parameters to traditional economic or monetary ones.

\section{ACKNOWLEDGEMENT}

We acknowledge the input and the support of all our colleagues at the LEAD programme of Leiden University and our colleagues at Padjajaran University in Bandung. In particular we are grateful for the inspiration and guidance from Prof. Dr. L.J. Slikkerveer as the director of LEAD, and Mr. K. Saefullah, M.A. as our sparring partner in the activities leading up to the conference.

\section{REFERENCE}

Alkire, S., Foster J. (2011) Understandings and misunderstandings of multidimensional poverty measurement, Journal of Economic Inequality, 9: 289-314, Springer Science

Alkire, S., Foster, J. (2011) Counting and multidimensional poverty measurement, Journal of Public Economics, 95 Nr. 95, 476-487, Elsevier

Alkire, S., Santos, M.E. (2014) Measuring Acute Poverty in the Developing World: Robustness and Scope of the Multidimensional Poverty Index, World Development, Nr. 59, 2014, Elsevier

Bekker, J.C.M. de (2015) Fieldwork Serengeti District, Mara Region, Tanzania, LEAD programme, 2015 (unpublished).

Bohannon, J. (2016) Satellite Images Can Map Poverty, Science Magazine, august 2016 (cf. Marshall Burke, Stanford University, Palo Alto, California).
Copestake, J. et al (2007) An analysis of Multiple Links Between Economic And Subjective Well-being Indicators, Using Data From Peru, ESRC Research Group, University of Bath, UK

Copestake, J., Camfield, L. (2009) Measuring Subjective Well-being in Bangladesh, Ethiopia, Peru and Thailand Using A Personal Life Goal Satisfaction Approach, ESRC, University of Bath

Deaton, A. (2005) "Measuring Poverty in a Growing World (or Measuring Growth in a Poor World)" Review of Economics and Statistics, 87(1): 1-19.

Deaton, A. (2008) Income, Health, and Well-Being around the World: Evidence from the Gallup World Poll, Journal of Economic Perspectives, Vol. 22, nr. 2, 2008.

Dutta, I. et al (2010) On Measuring Vulnerability to Poverty, Batch Economics Research Papers, University of Bath, U.K.

Edig van X. et al (2013) Poverty Assessment by ProxyMeans Tests: Are Indicator-Based Estimations Robust over Time? A Study from Central Sulawesi, Indonesia, Q. Journal of Int. Agriculture 52, No.1

Ferreira, F.H.G. et al (2015) Poverty Measures for The Developing World, World Bank, Published online 2015.

Gesthuizen, M. (2006) Determinanten van armoede: macro-economische omstandigheden, huishoudenskenmerken, gemeente en de buurt, Volume 81, Nr. 4, Radboud University Nijmegen

Joliffe, D., Prydz, E.B. (2016) Estimating International Poverty Lines from Comparable National Thresholds World Bank, Development Research Group Poverty and Inequality Team March 2016

Inst. Nac. de Estadistica (2006) Poverty and its Measurement The presentation of a range of methods to obtain measures of poverty, Spanish National Institute of Statistics (INE)

Ravallion, M. (2015) The Economics of Poverty: History, Measurement and Policy, at: World Economic Forum, published online 2016 (Oxford University Press) 
Roser, M. (2016) World Poverty, ourworldindata.org, published online (Oxford Martin School, U.K.).

Slikkerveer, L.J. et al (2012) Handbook for Tutors and Lecturers for Integrated Microfinance Management for Poverty Reduction in Indonesia, EVD, Min. of Econ. Affairs, The Netherlands

Vijaya, R. et al (2014) Moving from the Household to the Individual: Multidimensional Poverty Analysis World Development, Vol. 59, 70-81, 2014, Elsevier

Table 1: Checklist for exploratory semi-structured interviews in Peru

1. Goals: Let's suppose that a person would like to move to live here. What things do they need to be happy? What things are necessary to be happy?

2. Resources: How do they get those things? (Ask for each goal mentioned by the respondent).

3. Emotions (individual level): How do you feel in relation to...? (Ask this for each goal mentioned by the respondent).

4. Emotions (collective): How do people of this community feel about....? (Ask this for each goal mentioned by the respondent)

5. Values: Who are the people do you most admire in this community? (Alternative question for non-formal comprehension: Who are the best persons of this community? What are the things that you admire in this person (Ask for each person mentioned).

6. Social networks: Where do you find support when needed?

7. Happiest life episodes: What were the happiest moments of your life?

8. Unhappiest life episodes: What were the unhappiest moments of your life?

source: Copestake \& Camfield, 2009, Un. of Bath, UK

Table 2: The deprivation thresholds of those who are both MPI poor and destitute

\begin{tabular}{|c|c|c|c|}
\hline Dimension & Indicator & Deprived if... & Relative Weight \\
\hline \multirow{2}{*}{ Education } & Years of Schooling & No household member has completed at least one year of schooling $(>=1)$. & $1 / 6$ \\
\hline & Child School Attendance & No child is attending school up to the age at which they should finish class 6 . & $1 / 6$ \\
\hline \multirow[b]{2}{*}{ Health } & Child Mortality & 2or more children have died in the household. & $1 / 6$ \\
\hline & Nutrition & $\begin{array}{l}\left.\text { Severe undernourishment of any adult (BMIK } 17 \mathrm{~kg} / \mathrm{m}^{2}\right) \text { or any child } \\
(-3 \text { standard deviations from the median). }\end{array}$ & $1 / 6$ \\
\hline \multirow{6}{*}{$\begin{array}{l}\text { Living } \\
\text { Standard }\end{array}$} & Electricity & The household has no electricity (no change). & $1 / 18$ \\
\hline & Improved Sanitation & There is no facility lopen defecation). & $1 / 18$ \\
\hline & Safe Drinking Water & $\begin{array}{l}\text { The household does not have access to ssfe drinking water, or safe water is more than a } \\
\text { 45-minute walk (round trip). }\end{array}$ & $1 / 18$ \\
\hline & Flooring & The household has a dirt, sand, or dung floor (no change). & $1 / 18$ \\
\hline & Cooking Fuel & $\begin{array}{l}\text { The houssehold cooks with dung or wood } \\
\text { (coallignite/charcoal are now non-deprived). }\end{array}$ & $1 / 18$ \\
\hline & Assets & The household has no assets (radio, mobile phone etc.) and no car. & 1/18 \\
\hline
\end{tabular}

Source: AF method-Alkire \& Foster - c.s. OPHI, Oxford 2016
World Bank Group (2011) Measuring income and poverty using Proxy Means Tests, Social Protection and Labour Team, Dhaka, Bangladesh

White, S. and Pettit, J. (2004) Participatory Approaches And The Measurement of Human Well-being, ESRC Research Group, University of Bath, UK 
Tabel 3. SES Categorization

\begin{tabular}{|c|c|c|c|c|c|c|c|c|}
\hline SES_3.8 & $<\mathbf{5 0}$ & \begin{tabular}{|l|}
$50 \_100$ \\
\end{tabular} & 100_150 & 150_200 & 200_250 & $250>$ & tot & share \\
\hline very poor & 10 & & & 2 & & & 12 & $4,0 \%$ \\
\hline poor & 61 & 19 & 3 & 9 & 3 & 1 & 96 & $32,0 \%$ \\
\hline average & 25 & 36 & 13 & 40 & 25 & 43 & 182 & $60,7 \%$ \\
\hline rich & & & & 3 & 2 & 4 & 9 & $3,0 \%$ \\
\hline very rich & & & & & & 1 & 1 & $0,3 \%$ \\
\hline total & 96 & 55 & 16 & 54 & 30 & 49 & 300 & $100,0 \%$ \\
\hline very poor & $83,3 \%$ & $0,0 \%$ & $0,0 \%$ & $16,7 \%$ & $0,0 \%$ & $0,0 \%$ & $100,0 \%$ & \\
\hline poor & $63,5 \%$ & $19,8 \%$ & $3,1 \%$ & $9,4 \%$ & $3,1 \%$ & $1,0 \%$ & $100,0 \%$ & \\
\hline average & $13,7 \%$ & $19,8 \%$ & $7,1 \%$ & $22,0 \%$ & $13,7 \%$ & $23,6 \%$ & $100,0 \%$ & \\
\hline
\end{tabular}

Source: Fieldwork in Serengeti by the author

\section{Table 4. Variable measurements}

\begin{tabular}{|l|c|c|c|l}
\multicolumn{1}{c}{ measurement } & Scaling & Level & sphere & \multicolumn{1}{c}{ category } \\
\hline Income & Interval & Household & Monetary & Objective \\
\hline Consumption & Interval & Household & Monetary & Objective \\
\hline GDP per capita & Interval & Country & Monetary & Constructed \\
\hline Life Satisfaction & Ordinal & Individual & Mental & Subjective \\
\hline Well-being & Ordinal & Individual & Mental & Subjective \\
\hline Assets (L \& L*) & Nominal & Household & Material & Objective \\
\hline Health status & Ordinal & Individual & Physical & Subjective \\
\hline Health care system & Nominal & Individual & Mental & Subjective \\
\hline Infant / child mortality & Ratio & Household & Physical & Objective \\
\hline Life expectancy ** & Ratio & Individual & Physical & Constructed \\
\hline Education level & Ordinal & Individual & Mental & Objective \\
\hline School attendance*** & Ratio & Individual & Mental & Objective \\
\hline Household size & Absolute & Household & Physical & Objective \\
\hline Perceived status (econ.) & Nominal & Household & Mental & Subjective \\
\hline Housing material & Nominal & Household & Material & Objective \\
\hline Roofing material & Nominal & Household & Material & Objective \\
\hline Floor material & Nominal & Household & Material & Objective \\
\hline Safe water source (pot.) & Nominal & Household & Material & Objective \\
\hline Road accessibility & Nominal & Household & Material & Objective \\
\hline Energy consumption \# & Interval & Household & Material & Objective \\
\hline Safety \& Security \#\# & Nominal & Household & Mental & Subjective \\
& & & & \\
& & & \\
\hline
\end{tabular}

*Land and Livestock **possibly adjusted for age-group ***access as well proportional use \# MPI uses cooking fuel separately, \#\# considered either legally, physically or psychologically.(de Bekker, 2016) 